\title{
Effectiveness of Pharmacist Intervention (SAHELI) on Family Planning, Maternal Care and Child Care Among Rural Women
}

\author{
Dilip Chandrasekhar, Aswathi Shaji, Ardra Mariet Jose, Asifa Abdul Kareem, Levin Thomas \\ Department of Pharmacy Practice, Al Shifa College of Pharmacy, Perinthalmanna, Kerala, INDIA.
}

\begin{abstract}
Background: Due to low literacy rates and poor economic status rural women are either completely or partially unaware about modern Family Planning techniques and proper scientific maternal care and child care. "SAHELI"- Scheme to Aware Help and Empower Ladies in India was introduced in this context. It offers rural women, a complete assistance in learning modern FP techniques and practicing proper reproductive or sexual health care. Objectives: To assess the knowledge regarding Family Planning, Maternal Care and Child Care among rural women and to educate, aware and empower them regarding Family Planning, Maternal Care and Child Care. Methods: A quasi experimental study with 6-month duration was conducted among 140 women in the age group 15-45, in a rural area of Kerala state, India to evaluate the effectiveness of pharmacist intervention in Family Planning, Maternal Care and Child Care among rural women. Result: Before intervention, 53.8\% of the subject did not have knowledge about any methods of contraception, but after intervention all the subjects had knowledge about two or more methods. There was a significant improvement in family planning, maternal care and child care knowledge after intervention with a $p<0.05$. Paired t-test shows the mean
\end{abstract}

total score for knowledge for FP, maternal care and child care for pre-intervention: $117.48 \pm 10.53$ and post-intervention: $170.71 \pm 5.45$. Conclusion: The study clearly conveyed that majority of rural women were unaware about the Family Planning methods, Maternal Care and Child Care practices. The scheme has got a great acceptance by the rural women and they showed great enthusiasm and interest in acquiring more knowledge. This can be attributed to the care of pharmacist/community services in India and the perceived role of a pharmacist in the health care set up.

Key words: Child Care, Family Planning Services, Maternal Care.

Correspondence:

Dilip Chandrasekhar*, Professor and Head, Department of Pharmacy Practice, Al Shifa College of Pharmacy, Perinthalmanna, Kerala, INDIA.

Phone: +919447252670

Email: dillu7@gmail.com

DOI: 10.5530/jyp.2018.10.20

\section{INTRODUCTION}

According to World Health Organization (WHO), family planning (FP) is the conscious effort made by couples and individuals to plan for and attain desired number of children and to regulate the spacing and timing of childbirths. It is achieved through proper use of contraceptive methods and treatment of involuntary infertility. ${ }^{1}$ According to the recent statistics of United Nations Population Fund, 222 million among the 867 million women of childbearing age in developing countries do not have access to any modern contraceptives. ${ }^{2}$ In India, rural women face many social, economic and cultural inhibitions to share their sexual health concerns and access modern family planning methods.

By promoting family planning programs, it will be able to reduce population growth rate, achieve desired family size, and avoid unintended or mistimed pregnancies and space between children. FP not only aims at population stabilization but also helps in reducing maternal morbidity and infant and child mortality. ${ }^{3}$

The Government of India is providing many FP services at the village level, state level and higher levels and these services are provided by ASHAs (Accredited Social Health Activists) health volunteers, nurses, and doctors. The various services include the following: Home Delivery of Contraceptives: - the contraceptives are delivered at doorstep of beneficiaries by the ASHAs at very low prices. Ensuring Spacing at Birth [ESB]: This new scheme aims at counseling newly married couples to ensure spacing of two years after marriage and couples with one child to have spacing of three years after the birth of first child. The Ministry of Health \& Family Welfare has introduced short term IUCD (5 years affectivity), Cu IUCD 375 under the National Family Planning Program. A new method of IUCD insertion (post-partum IUCD insertion) has been introduced by the Government. Pregnancy Testing Kits: NRHM (National Rural Health Mission) launched Nishchay: Home based pregnancy kits (PTKs) are available at sub centers and also distributed by ASHAs. Emphasis on Postpartum Family Planning (PPFP) Services: Insertion of IUCD during the postpartum period, known as Postpartum Intrauterine Contraceptive Device (PPIUCD), is being focused to address the high unmet need of spacing during postpartum period. ${ }^{3}$

Maternal health refers to the health of women during pregnancy, childbirth and postpartum period. The major direct cause of maternal morbidity and mortality include hemorrhage, infection, high blood pressure, unsafe abortion, and obstructed labor. ${ }^{4}$ Among married women in rural India, the median age at which they first give birth is 19.6 years and nearly half of married women have had at least one child during the age $15-19 .^{5}$ The current maternal mortality rate in India is 174 deaths per 100,000 live births. Though the average maternal mortality rate of Kerala is better than every other state, it is unacceptably high compared to the international standards and has been relatively stagnant for the past few years. ${ }^{6}$ According to WHO, $30 \%$ of children under the age of five are estimated to be stunted, $18 \%$ have low-weight-for-height ratio, and 43 million children are overweight. Nearly 9 million children die every year from preventable diseases and infection, the largest killer being diarrheal disease. Infant mortality rate in India is 38 deaths for every 1000 live births. Breastfeeding is the first crucial step to ensure good health in infants.?

So, this scenario demands a significant need for health care programs aiming at improving the knowledge about FP, maternal care and child 
care. Even though many government schemes are available for meeting the unmet need of family planning and other maternal care and child care services, these are not properly reaching the people in remote and rural areas as they lack knowledge about these services. But many studies have proven that rural women are totally unaware of modern family planning techniques, maternal and child care. The main limitation of this study is rural women are too shy to participating in these studies and are unwilling to share their sexual problems. They consider disclosing their personal life as a taboo. This study was aimed at improving the awareness among rural people about the FP techniques, the importance of maternal care and child care through proper intervention.

\section{METHODS}

The study was carried out in a rural area of Kerala state in India. A quasiexperimental design was used to evaluate the effectiveness of pharmacist intervention in family planning and reproductive morbidity among rural women. The study spanned over duration of six months.

The study was approved by the ethical committee of the hospital where the investigators work or study and an official consent was provided by the Managing Director for the purpose of conducting the study. It was certified that the Institutional Ethics Committee met on 03/02/2015 approved the proposal for the dissertation as per letter no IEC/ASH/2015/ $\mathrm{PD} / 15$ dated 03/02/2015.

A pilot study was conducted to calculate the sample and to know the ease of data collection using the questionnaire developed for the study.

The study was conducted among165 females in the reproductive age group 15-45 years but only 140 subjects received intervention. 25 subjects withdrew from the study due to lack of willingness to participate in the study. Investigators obtained written informed consent from the participants. Investigators always considered the issues of privacy and confidentiality of all study participants without disclosing their identity. Women of reproductive age 15-45yrs were included in our study while seriously ill women (not related with Gynecological morbidities), psychiatric patients were excluded from our study. A data collection form was developed in order to collect the necessary information relevant to the study. The survey instrument was prepared in English and then translated to Malayalam. Later the questionnaire was validated both externally and internally by healthcare professionals. The questionnaire consists of demographics of participants and five-point likert scale statements for assessing knowledge about family planning, maternal care and child care. All the study subjects were interviewed for their demographic details which included information such as participant names, age, religion, height, weight, educational status, employment status, marital status, age of marriage, spouse age, educational qualification and employment status, number of pregnancy, number of cesarean, number of normal delivery, Number of children, Abortion history.

The scale developed by A.K.Sood and B.K.Nagla was used to assess the knowledge of rural women regarding family planning, child care and maternal care [8]. This study tool was chosen because similar study was conducted in similar population. In this study, both positive and negative statements were prepared in relation to maternal and child health care, family planning beliefs and cultural practices. A five-point Likerttype of scale was used for scoring each statement (fully disagree, disagree to some extent, could not decide, agree to some extent and totally agree). Each positive statement was given a score of 5 for total agreement, 4 for partial agreement, 3 for could not decide, 2 for partial disagreement and 1 for total disagreement while in the case of negative statement a score of 5 was given to total disagreement, 4 for partial disagreement, 3 for could not decide, 2 for partial agreement and 1 for total agreement. Over all, there were 21 statements related to child-care, 6 on maternal care and 10 on family planning. There were 10 positive and 27 negative statements. The maximum possible score was 185 .

After assessing the knowledge of the participants they were subjected to the intervention program SAHELI- SCHEME TO AWARE HELP EMPOWER LADIES IN INDIA which was an open group counseling program providing knowledge about modern family planning techniques and its importance, maternal care and child care.

After the intervention was provided the subjects were again assessed for improvement in knowledge using the same questionnaire.

\section{Study Procedure}

The study was carried out in three phases.

Phase 1(pre-interventional phase): Duration of this phase was 2 and half months involved only data collection without any interventions. The data were collected by visiting each participant's household. The questionnaire was filled by the interviewer which took about 15-30 minutes. Using the validated questionnaire and scores given, the current knowledge about family planning, maternal care and child care were measured and the areas where they needed improvement were assessed.

Phase 2(interventional phase) "SAHELI": Based on the assessment of the pre-interventional phase, the areas where the participants needed help, awareness, and empowerment were assessed. So the investigators, as an intervention developed a novel approach called "SAHELI" - Scheme to Aware Help and Empower Ladies in India. This program aimed to help, educate, and empower rural women in areas of family planning, child care and maternal care. The program involved group counseling sessions and classes led by pharmacists. All the participants who were unable to participate in the program were given counseling by visiting them personally. The group counseling presentations were prepared scientifically to meet the participants need, that is, they were audited by a multidisciplinary healthcare teams. The topics included need of family planning, various family planning methods to meet the individual couple's needs, method of using family planning measures, possible side effects and its contraindications to family planning methods, government projects and supply details of family planning methods, maternal care facts and healthy practices that must should be followed, child care including breast feeding and nutrition.

Phase 3(post interventional phase): During this phase, the effectiveness of the intervention was assessed. Improvement in the knowledge about family planning, child care and maternal care were assessed using the same questionnaire which was used in the pre-interventional phase. The data were collected by the interviewer by visiting the participant's household.

Data input was done by the 3 investigators and the discrepancies resolved by discussion with supervisors. The data was recorded into the SPSS version 20 Windows version and was used to perform the statistical analysis of the data. The tests used were paired t test for comparison of demographical variables, $\chi 2$ test for testing the association of qualitative variables under study, ANOVA technique for comparison for scores under different variables, Correlation and Regression analysis for testing the independence of quantitative variables. The level of significance used for the statistical analysis was 0.05 .

\section{RESULTS}

An aggregate of 140 females were enrolled for the study. Mean age of the study population $=29.73 \pm 9.05$ years. It was found during the study that $39 \%$ of the subjects had completed their secondary education, $27 \%$ with primary education and a least proportion of subjects were graduated (UG-8\%, PG-3\%).Among them, majority (87\%) were unemployed, $8 \%$ professionals and $5 \%$ non-professionals. The knowledge about FP was 
found high among professionals compared to unemployed women. The subjects followed different religions viz. Hindu (36\%), Christian (39\%) and Muslim (25\%). It was found that the knowledge and acceptance of contraceptives are high among Christians and Hindus compared to Muslims. [Table 1]

Before the intervention majority of the samples showed a partial disagreement (29\%) and many of them (26\%) had no idea about spacing between pregnancies but after intervention $58 \%$ of the subjects showed total agreement to spacing between pregnancies. Before the intervention $55 \%$ of the subjects were against abortion of unwanted pregnancies but after the intervention $63 \%$ of the subjects showed agreement to abortion of unwanted pregnancies. Before the intervention $86 \%$ of the subjects believed that using family planning methods would disrupt the marital pleasure. But after the intervention, $97 \%$ of the subjects understood that it was a misconception. $80 \%$ of the subjects were unaware before intervention that the gender of the child was determined by father not by mother but after intervention $97 \%$ of the subjects were aware about the fact. [Figure 1]

Before the intervention $54 \%$ of the subjects had no knowledge about a single method of contraception, $36 \%$ had knowledge about oral pills, condoms and intra uterine devices, and $10 \%$ of the subjects had knowledge about more than 4 methods of contraception. But after intervention $56 \%$ had knowledge about oral pills, condoms and intra uterine devices, and $44 \%$ of the subjects had knowledge about more than 4 methods of contraception. [Figure 2]

The most common method of contraception adopted by the subjects were natural method (47\%) \{Coitus interruptus (28\%) and Periodic abstinence (19\%) $\}$ and modern methods were used by only $13 \%$ (IUDs$8 \%$, Condoms-3\%, Oral pills-2\%). The important reasons for not using contraceptives were lack of knowledge about FP (29\%), desire for more children (18\%), natural method adaption (13\%), worries about the side effects (14\%), absence of a partner in sex (19\%) and post-partum breast feeding by mothers (3\%).

Before the intervention $21.4 \%$ of the women considered pregnancy before 18 years is very healthy for both the child and the mother but after intervention almost all the subjects were fully aware about the problems associated with pregnancy before 18 years. The graph also reveals that before intervention the subjects were unaware about the importance of rest during pregnancy but after the intervention almost all the subjects fully or partially agreed on taking proper rest during pregnancy. Before the intervention $35 \%$ of the subjects considered iron, folic acid tablets were harmful for the fetus during pregnancy but after intervention almost all the subjects were aware about the importance of iron folic acid during pregnancy. Similarly, the subjects before the intervention believed that normal diet is required during pregnancy but post intervention they showed disagreement to this statement. [Figure 3]

Before the intervention a proportion of the subjects showed either partial or total agreement to colostrums as an unhealthy secretion but after the intervention the subjects were fully aware about the importance of colostrums. It was found that before the intervention 39\% of subject believed that child should not be breast fed when mother is sick, but after the intervention such misbelieves were completely erased. Even before the intervention, almost all the subjects were aware about the importance of breast milk over bottle milk. The pre-intervention assessment revealed that most of the subjects were unaware about when to add top feeds in the child's diet, but the intervention made them aware that top feeds should be added to children's diet after 4-6 months of birth. More than $70 \%$ of the subjects considered diarrhea as a minor problem before receiving intervention. But after receiving intervention they were totally aware about the consequences of diarrhea in children. [Figure 4]

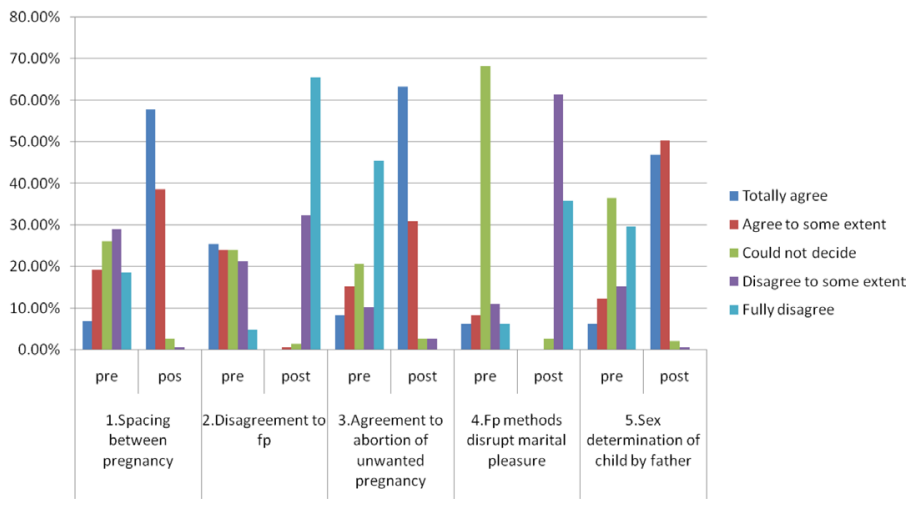

Figure 1: Knowledge about Family planning

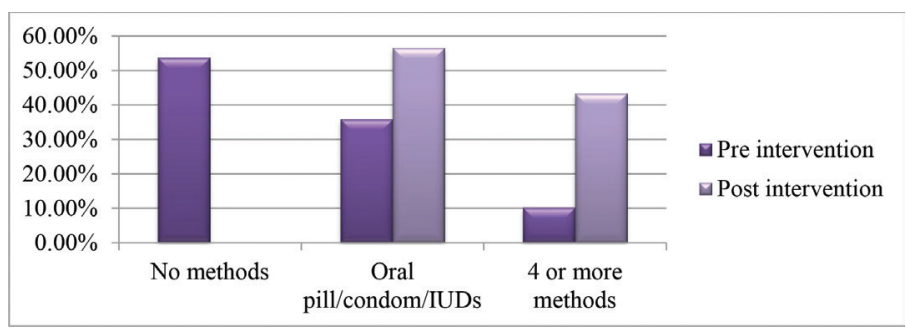

Figure 2: Knowledge about contraceptives

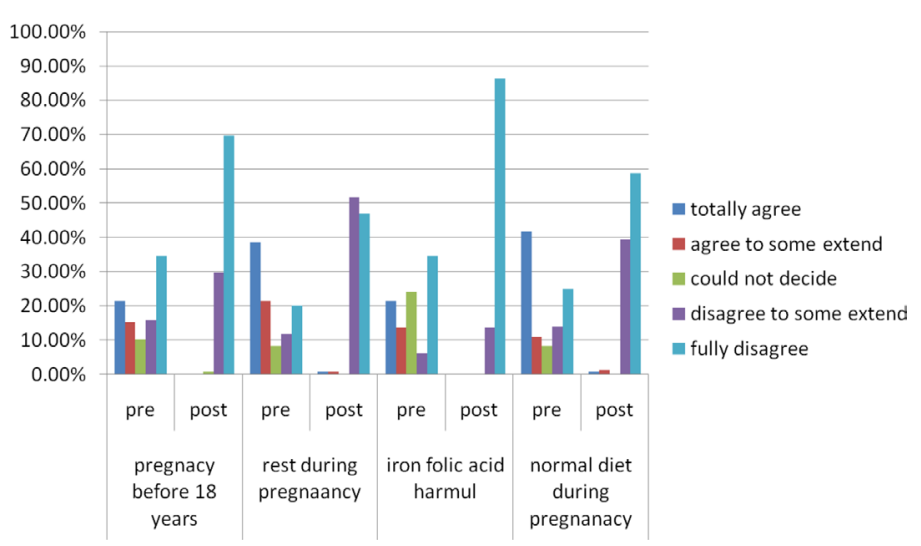

Figure 3: Knowledge about maternal care

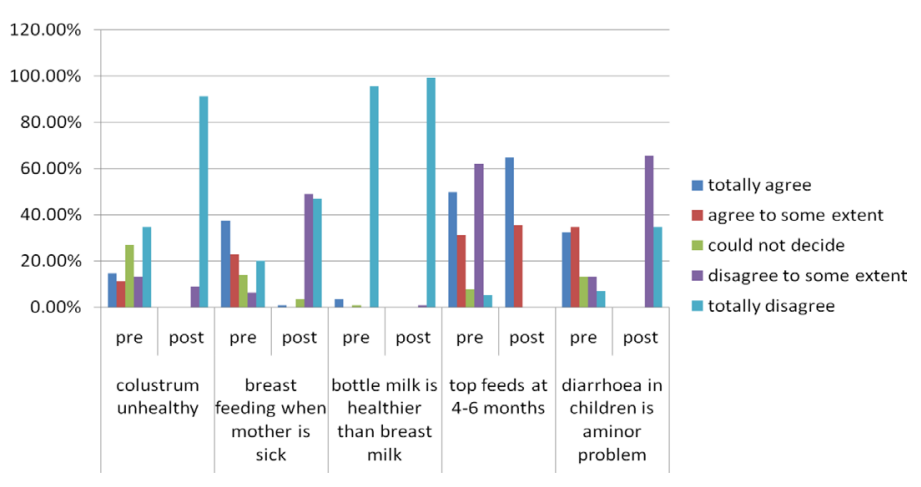

Figure 4: Knowledge about child care 


\begin{tabular}{ccc} 
Table 1: Demographic Detail & & \\
\hline & DEMOGRAPHIC DETAILS & \\
\hline Educational Status & Uneducated & $3 \%$ \\
& Primary Education & $27 \%$ \\
& Secondary Education & $39 \%$ \\
& Higher Secondary Education & $21 \%$ \\
Marital Status & UG & $8 \%$ \\
& PG & $2 \%$ \\
Religion & Married & $77 \%$ \\
& Unmarried & $19 \%$ \\
& Divorced & $4 \%$ \\
Employment Status & Hindu & $36 \%$ \\
& Muslim & $25 \%$ \\
& Christian & $39 \%$ \\
& Unemployed & $87 \%$ \\
& Professional & $8 \%$ \\
\hline
\end{tabular}

\begin{tabular}{clc}
\multicolumn{2}{l}{ Table 2: Knowledge scoring } \\
\hline \multicolumn{2}{c}{ SCORING } & \\
\hline Family Planning & Pre-Intervention Score & $25.57 \pm 4.52$ \\
& Post Intervention Score & $44.85 \pm 2.5$ \\
Maternal Care & Pre-Intervention Score & $21.07 \pm 2.99$ \\
& Post Intervention Score & $28.48 \pm 1.19$ \\
Child Care & Pre-Intervention Score & $68.78 \pm 6.98$ \\
& Post Intervention Score & $92.26 \pm 3.69$ \\
\hline
\end{tabular}

\section{Paired t-test:}

T value: 61.06

$\mathrm{P}<0.001$ (Significant)

So overall the paired-t test value shows that knowledge about family planning, maternal care and child care was higher after the intervention. [Table 2]

- Spearman correlation:

- Between pre-intervention score and education level of subject

- Correlation coefficient: 0.432

The positive indicates that as education level increases, the pre-intervention score also increases.

- Correlation is significant with $\mathrm{p}<0.001$

- Spearman correlation: (between employment status \& pre-intervention score)

- Correlation coefficient: $0.287 \mathrm{P}<0.001$

This indicates that professional women had high pre-intervention score.

\section{DISCUSSION}

This study mainly aimed at improving the knowledge of family planning, maternal care and child care among rural women. Majority of the study population have only primary or secondary education. Most of them were unemployed. Study conducted by the Ljiljana Antic and study by Alan Emond had similar results. ${ }^{9}$ These women were living inside their houses totally unaware of their sexual rights or proper family planning methods. There were only a small proportion of well-educated and professional women who had adequate knowledge about family planning and its importance in their social life.

Not only education has an impact on family planning but also religious beliefs play a fundamental role in family planning. The study revealed that the Muslim community did not promote the use of contraceptives but the level of acceptance of contraceptives was found higher among Christian and Hindu women. A Study done in Orissa by Sahoo H did not show any association between religion and contraceptive use whereas in Dakshina Kannada study, acceptance of contraceptive method was more among Hindus compared to Muslims ${ }^{10,11}$ Modern methods of contraceptives were used by very small proportion of the study population. Majority of the subjects either used natural methods like coitus interuptus and periodic abstinence or did not consider contraception at all. This is similar to the study conducted by Ljiljana Antic. ${ }^{9}$

The pre-interventional knowledge assessment phase revealed that even most of the married women had no idea about the concept of contraception. Also, this phase revealed that many girls get married at an early age and they were not provided with any pre-marital education about family planning methods or its importance and how it affects their social life or their carrier.

Some of these rural women were highly insecure about sharing the details of their sex life. They considered disclosing their personal life as a taboo. The pharmacists took so much effort to convince them that this study was aimed at the betterment of their health.

According to the present study, reasons for not practicing any methods of family planning were lack of information, which is somewhat similar to the results of the study by Ram Rama et al (2001-2003). ${ }^{12}$ Only a small proportion of the women had a basic knowledge of family planning from schools, pre-marital courses and healthcare professionals. On a contrary to the study by Rozina Mustafa, family planning knowledge was provided by health personnel to the subjects and a few of them heard it from their social circle. ${ }^{13}$ Before the intervention, $53.8 \%$ of the subject did not have any knowledge about any method of contraceptives. But after the intervention, all those subjects had acquired basic knowledge about at least a single method of contraceptives. It was found that there is a significant association between the education level, knowledge and use of contraceptives. The finding is consistent with the findings of Khokhar et al (2000) and Saini et al (2007) who found increase in current use of contraceptives with increasing education. The pre-intervention score for knowledge was found to be high among young women compared to older women. ${ }^{14,15}$

Rural women had many misconceptions about the care during pregnancy and child care. They believed that working hard during pregnancy paves way for normal delivery. They even believed that taking rest during pregnancy might lead to complications during delivery. They were also not aware about the importance of the intake of extra vitamins and nutrients during pregnancy. They also did not even consider spacing between pregnancies as an important issue. These women were unaware about the importance of colostrum for the newborns. They considered it as an unhygienic yellow secretion of the mammary glands refused to feed it to the newborns. Also, they did not consider the importance of vaccination for children. Some of them had misconceptions that vaccination causes illness in children.

In the light of the details collected in the pre-intervention phase a novel approach on healthcare management by pharmacists for rural women named "SAHELI" (Scheme to Aware Help and Empower Ladies in India) was introduced with the aim of uplifting the lives of rural women by educating regarding the modern family planning techniques, maternal care and child care. During the intervention program SAHELI subjects 
were provided with open counseling on methods of family planning and their importance in their social life, the care and diet during pregnancy, importance of breast feeding and vaccination in children and other child care. The post-interventional analysis showed that SAHELI was successful in educating rural women about the importance of planning their family, taking good care of their reproductive health, maternal care and child care. Also, the post-interventional study revealed that rural women had a positive attitude towards family planning. Their knowledge scores were improved compared to the pre-intervention study.

\section{CONCLUSION}

So as a conclusion SAHELI had a great impact on the rural women. This helped them to improve their quality of living in terms of reproductive health and thus helped them in empowerment. From the feedback received, it was clear that SAHELI was able to change the attitude and knowledge of rural women regarding the modern family planning techniques and importance of maternal care and child care. The attitude in this context is mentioned as the study population showed unwillingness to participate in the study during the pre-interventional phase because of their inhibitions and lack of knowledge. SAHELI should be drawn out to a wider canvas so as to provide its services to more people especially in discrete and rural areas. This can help in creating collaboration between general public, pharmacists with the help of local health centers.

\section{REFERENCES}

1. WHO's certified [Internet]. Family planning, c2015. Available from: http://www who.int/mediacentre/factsheets/fs351/en/ (accessed on 8/2/2016)

2. United Nations Department of Economic and Social Affairs. Population Division [Internet]. World Contraceptive Patterns 2013. Available from: http://www. un.org/en/development/desa/population/publications/family/contraceptive-wallchart-2013.shtml (accessed on 8/2/2016)
3. Annual report 2013-2014, chapter 9 Family planning, ministry of health and family welfare, family planning scenario (NHFS, DLHS).

4. Health Policy Kerala [Internet], Health \& Family Welfare Department Government of Kerala. c2013. p. 11-2. Available from: http://dhs.kerala.gov.in/docs/ draftpolicy.pdf(accessed on 14/2/2016)

5. Sabarwal S, Santhya KG. Treatment-seeking for symptoms of reproductive tract infections among young women in India. Int Perspect Sex Reprod Health. 2012;38:90-8

6. CHILD Protection and Child Rights, Vulnerable Children, Children's Issues, Child Health and Nutrition. Available from: http://www.childlineindia.org.in/childhealth-and-nutrition-india.htm (accessed on 14/2/2016)

7. Centre for Reproductive Rights [Internet]. The World's abortion Law Map Update. c2013. Available from: http://www.reproductiverights.org/sites/crr.civicactions.net/files/documents/Abo rtionMap_Factsheet_2013.pdf (accessed on 14/2/2016)

8. Sood AK, Nagla BK. Development of a scale to assess maternal and child health and family planning knowledge level among rural women. Health and PopulationPerspectives and Issues. 2000;23(1):37-52.

9. Ljiljana A, Bosiljka D, Dejana V. Family Planning among Women in Urban and Rural Areas in Serbia. Srp Arh Celok Lek. 2013;141(11-12):794-9.

10. Sahoo H. Determinants of contraceptive use in Orissa: An analysis from National Family Health Survey III. Health and Population-Perspectives and Issues. 2007;30(3):208-21.

11. Padma M, Kamat A, Sajjan BS. Fertility pattern and family planning practices in a rural area in Dakshin Kannada. Indian Journal of Community Medicine 2003;28(1):15-18.

12. Ram R, el al. Study of Unmet Need for Family Planning Among Married Women of Reproductive Age Attending Immunization Clinic in a Medical College of Calcutta. Indian Journal of Community Medicine. 2003;25:01

13. Rozina M. Contraceptive Knowledge, Attitude, Practice among rural women, Journal of the College of Physicians and Surgeons Pakistan. 2008;18(9):542-5.

14. Khokhar A, Mehta M. Contraceptive use in women from resettlement area in delhi. Indian J comm. 2005;30(1).21-3

15. Saini NK, Bhasin SK, Sharma RY. Study of unmet need for family planning in a resettlement colony of east Delhi. Health Pop Perspect Issues. 2007;30(2):124-33.

Article History: Submission Date : 22-07-2017 ; Revised Date : 29-08-2017; Acceptance Date : 25-11-2017.

Cite this article: Chandrasekhar D, Shaji A, Jose AM, Kareem AA, Thomas L. Effectiveness of pharmacist intervention (SAHELI) on family planning, maternal care and child care among rural women. J Young Pharm. 2018;10(1):86-90. 